\title{
Der richtige Zeitpunkt
}

\section{Rouven Porz}

PD Dr. phil., dipl. biol., Direktion Medizin, Medizinethik Insel Gruppe AG (Bern), Gastwissenschaftler der VU Amsterdam,

Präsident der European Association of Centres of Medical Ethics (EACME) und Mitglied der Redaktion Ethik der SÄZ

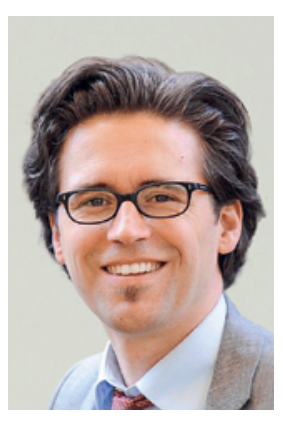

Der Bruder eines Freundes von mir ist sehr krank. Mein Freund ist verzweifelt. Der Bruder wird bald sterben. Mein Freund schreibt mir regelmässig E-Mails und beschwert sich über die Absurditäten des Medizinsystems. Obwohl sein Bruder gut behandelt würde, so zeige sich dennoch niemand für ihn wirklich verantwortlich. Ein Spezialist folge dem nächsten, und selbst auf der Onkologiestation würde sich keiner trauen, einmal über den kommenden Tod zu sprechen. Wann ist der richtige Zeitpunkt, um endlich über den Tod zu sprechen? Mit dieser Frage endet die letzte E-Mail meines Freundes. Ich weiss nicht, was ich antworten soll.

In unserer eigenen Familie war letztens auch jemand sehr krank. Unsere Odyssee begann beim «Hausarzt» des Patienten. Wichtig zu wissen, der Patient ist urteilsunfähig. Also begannen meine Frau und ich über den Patienten zu erzählen. Der Patient lag erschlagen daneben und hörte kaum zu. Der Arzt schien auch nicht zuzuhören - so unser Eindruck - und legte direkt los mit Abtasten, Drücken, Fläschelchen wurden vorbereitet zur Blutentnahme. Ein paar Tage später erneut ein Besuch beim selben Arzt. Ja, unser Patient sei wirklich sehr krank. Die Blutwerte seien nicht gut.

\section{Wann ist der richtige Zeitpunkt, um endlich über den Tod zu sprechen?}

Eventuell drohe ein Nierenversagen, oder vielleicht ein Darmtumor. Das erkläre die enorme Abgeschlagenheit, die Darmprobleme und den gefundenen Proteinverlust. «Wird er sterben?», fragte ich. Keine Antwort. Mhm, dachte ich, das war wohl noch nicht der richtige Zeitpunkt für diese Frage.

Wir wurden $\mathrm{zu}$ einem Ultraschallspezialisten überwiesen. Der Patient wurde narkotisiert, man traute ihm nicht zu, den Ultraschall gelassen durchzustehen. Die wenigen Bauchhaare wurden abrasiert. Meine vierjährige Tochter stand mit grossen Augen vor dem
Untersuchungstisch. Dem Patienten wurde vom Ultraschallspezialisten schon wieder Blut abgenommen, ausserdem Urin aus der Blase gezogen (mit einer Spritze) und Wasser aus dem Darmraum (mit einer Spritze). Mir wurde schlecht. Ich sagte: «Mir wird schlecht.» Der Spezialist lachte. Die Untersuchung ging weiter. Nein, er könne uns nicht genauer erklären, was er gefunden habe, es scheint, als würden die Nebennieren fehlen, aber vielleicht sei es auch ein Darmtumor. Er würde einen Bericht schreiben und an den zuweisenden Arzt schicken.

\section{Der Patient trank nicht mehr, ass nicht mehr und stand kaum mehr auf.}

Der Patient trank nicht mehr, ass nicht mehr und stand kaum mehr auf. Ganze 48 Stunden lang. In diesen 48 Stunden konnten wir seinen eigentlichen Arzt nicht erreichen. Kein Termin möglich, er würde zurückrufen, er rief nicht zurück. Verzweiflung. Was jetzt? Tierklinik? Notfall. Wir fanden eine neue Tierärztin. Aufgeregt schilderten wir die letzten 48 Stunden. Sie hörte einfach zu. Sie fragte nach. Sie las in Ruhe die Untersuchungsergebnisse des Spezialisten für Ultraschall. Dann sagte sie: «Ich fange jetzt an, ihren Labrador-Mischling zu untersuchen. Es ist noch nicht der richtige Zeitpunkt, um übers Sterben zu reden.» Ich war beeindruckt. Wieder Blutentnahme, diesmal aber sehr vorsichtig. Trotzdem wieder Übelkeit auf meiner Seite. "Mir wird schlecht.» "Dann setzen sie sich hin, Herr Porz. Hier ein Glas Wasser, draussen ein Stück Schokolade. Sie glauben nicht, wie viele Hundebesitzer uns hier umkippen.»

Zwei Tage später rief die Tierärztin uns an. Sie rief uns an! Wir mussten ihr nicht nachlaufen, nicht nachfragen. Sie rief an: «Gute Nachricht. Ihr Hund hat Morbus Addison. Wir geben jetzt Cortison, und dann kommt er wieder auf die Beine.»

Und die Moral von der Geschichte? Die Medizin ist manchmal un-menschlich. 